\title{
CRYSTAL GROWTH AND ELECTRO-OPTICAL CHARACTERIZATION OF BISMUTH TRI-IODIDE*
}

\section{APRIL 1974}

*WORK SUPPORTED UNDER CONTRACT NO. AT(26-1)-565 TO THE U.S. ATOMIC ENERGY COMMISSION.

This doctument is

PUBLICLYRELEASABLE tharesobilliams Aintartioning Oflicial

$08 / 15 / 2007$

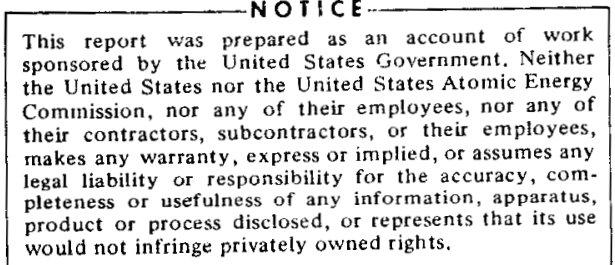

would not infringe privately owned rights. 


\section{EGG 565-134 \\ S-85-TP}

\section{CRYSTAL GROWTH AND ELECTRO-OPTICAL CHARACTERIZATION OF BISMUTH TRI-IODIDE}

by M.M. Schieber, T.J. Davies, H.A. Lamonds, W.F. Schnepple, P.T. Randtke, and R.C. Carlston

\section{APRIL 1974}

Submitted to the Journal of Applied Physics

This report is unclassified:

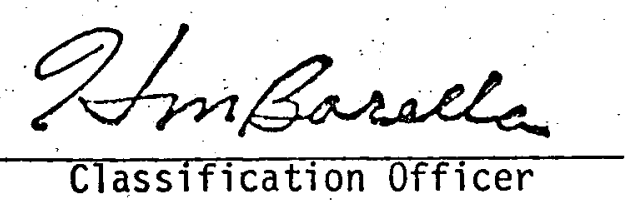




\section{NOTICE}

This report was prepared as an account of work sponsored by the United States Government. Neither the United States nor the United States Atomic Energy Commission, nor any of their employees, nor any of their contractors, subcontractors, or their employees, makes any warranty, express or implied, or assumes any legal liability or responsibility for the accuracy, completeness or usefulness of any information, apparatus, product or process disclosed, or represents that its use would not infringe privately-owned rights. 


\section{DISCLAIMER}

This report was prepared as an account of work sponsored by an agency of the United States Government. Neither the United States Government nor any agency Thereof, nor any of their employees, makes any warranty, express or implied, or assumes any legal liability or responsibility for the accuracy, completeness, or usefulness of any information, apparatus, product, or process disclosed, or represents that its use would not infringe privately owned rights. Reference herein to any specific commercial product, process, or service by trade name, trademark, manufacturer, or otherwise does not necessarily constitute or imply its endorsement, recommendation, or favoring by the United States Government or any agency thereof. The views and opinions of authors expressed herein do not necessarily state or reflect those of the United States Government or any agency thereof. 


\section{DISCLAIMER}

Portions of this document may be illegible in electronic image products. Images are produced from the best available original document. 


\section{ABSTRACT}

The purification and crystal growth from the vapor phase and some electrooptical characterization measurements of $\mathrm{BiI}_{3}$ are described. The sublimed boules had large single crystalline pieces which could be cleaved to give areas of about $1 \mathrm{~cm}$ in diameter and a thickness of about $1 \mathrm{~mm}$. The grown crystals were measured for transmission from $0.6 \mu \mathrm{m}$ to $50 \mu \mathrm{m}$, reflection from $0.6 \mu \mathrm{m}$ to $1 \mathrm{\mu m}$, energy band gap $\mathrm{E}_{\mathrm{g}}$, index of refraction, and some photoconductivity measurements. The $\mathrm{E}_{\mathrm{g}}$ at room temperature and $78^{\circ} \mathrm{K}$ was found to be 1.78 and $2.09 \mathrm{eV}$, respectively, and the complex index of refraction at $1 \mu \mathrm{m}$ wavelength is $N=3.13-i\left(3.2 \times 10^{-5}\right)$. 


\section{INTRODUCTION}

$\mathrm{Bi} \mathrm{I}_{3}$, with an energy gap of $\sim 2.00 \mathrm{eV}$ at room temperature ${ }^{1,2}$ is relatively little known and its methods of growth have not yet been reported. Crystallographically, it seems to have two polytypes but the stable form is rhombobedral having a unit cell in the hexagonal lattice of $a=7.5 \AA$ and $c=20.7 \AA$ crysta $^{3}$ within the space group $C_{3_{i}}^{2}-R 3$. The optical properties of $\mathrm{Bi}_{3}$ have been studied in the USSR, and references 1 and 2 seem to be the most recent publication on its physical properties. The compound is also known as a photoconductor. ${ }^{1,4}$ Its melting point is $407.7^{\circ} \mathrm{C}^{5}$ and its extrapolated boiling point is $542^{\circ} \mathrm{C} .{ }^{6,7}$

This paper will describe: 1) vapor-phase purification and growth, and 2) characterization of the grown $\mathrm{BiI}_{3}$ crystals.

\section{VAPOR-PHASE PURIFICATION AND GROWTH OF BiI3}

The starting Baker reagent $\mathrm{BiI}_{3}$ powder has been evacuated in a quartz ampoule to about 10-5 torr and introduced in a two-zone furnace where the upper temperature is $420^{\circ} \mathrm{C}$ and the lower temperature is $300^{\circ} \mathrm{C}$. Shiny metali ic looking platelets of $\mathrm{BiI}_{3}$ perpendicular to the hexagonal " $\mathrm{C}$ " axis are grown from a first sublimation brown-colored residue of unevaporated BiOI is left behind. The BiOI is probably formed as a result of the hydrolysis of $\mathrm{BiI}_{3}$, so that $\left(\mathrm{BiI}_{3}\right)_{v}+\left(\mathrm{H}_{2} \mathrm{O}\right)_{V}$ $=(\mathrm{BiOI})_{S}+(2 \mathrm{HI})_{V}$. The emission spectrographic analysis of raw and purified material is shown in Table 1.

Table 1. Spectrochemical analysis of $\mathrm{BiI}_{3}$ crystals in ppm

\begin{tabular}{|l|c|c|c|c|}
\hline & Mg & Si & Ca & Other Elements \\
\hline Amorphous Raw Material & 2.60 & 29 & $<2.00$ & Not Detected \\
First Sublimation & 1.50 & $<1.00$ & $\begin{array}{c}<2.00 \\
\text { Fourth Sublimation }\end{array}$ & \multicolumn{3}{|c|}{$\begin{array}{l}\text { Not Detected } \\
\text { Not Detected }\end{array}$} \\
\hline
\end{tabular}

Crystals of $\mathrm{BiI}_{3}$, after four or five cycles of purification, were introduced in quartz ampoules of $15-\mathrm{mm}$ diameter and evacuated to $10^{-5}$ torr. The ampoule is placed in a two-temperature-zone furnace where the source is at 380 
to $400^{\circ} \mathrm{C}$ and the cold end of the ampoule in the temperature gradient is at 320 to $350^{\circ} \mathrm{C}$, as shown in Fig. 1. A boule is obtained after 48 hours which is polycrystalline at the colder end, but at the hot end gradually becomes single crystalline by a self-seeding procedure. The self seeding is interpreted as stemming from the disappearance of the smaller grain by a c-oriented seed grain whose growth prevails, since $c$ is the easy axis of growth. A typical boule is shown in Fig. 2. The single-crystal boule can be easily cleaved perpendicular to the "c" axis. Source growth experiments were also performed by using a seed crystal of a previously grown boule, allowing the growth of single crystalline boules of 50-mm long and 13-mm diameter.

\section{CHARACTERIZATION OF THE BiI3 CRYSTALS}

A twice purified, vapor grown crystal of $\mathrm{Bi}_{3}$ cleaved from a larger boule has been studied by: 1) x-ray diffraction, 2) optical transmission and optical reflection, and 3 ) gamma-ray detection.

\subsection{X-Ray Studies}

Both Laue back-reflection and x-ray diffractometer methods were used. The sample was mounted for the Laue studies, so that the pinhole beam was perpendicular to the flat face. A back reflection Laue study was then made using the white radiation from a copper $x$-ray target. The sample-to-film distance was $30 \mathrm{~mm}$. The beam diameter impinging on the sample was $1-2 \mathrm{~mm}$ in diameter. Severe imperfections and severe twinning show up in this Laue study. A high level of strain, which may be due to the cleavage operation, is present in the wafer causing diffuse streaks to appear. As considerable imperfection was observed in the Laue study, the sample was also scanned in the x-ray diffractometer to indicate whether crystallites showing other orientations were present. The signal was obtained for this study covering an entire diameter of the wafer, indicating that the wafer is oriented with the " $c$ " axis perpendicular to the wafer face. The diffractometer study confirms that [0001] orientation occurs completely across the crystal. Additional minor peaks indicate that a few small crystallites showing other orientations are present. Unidentified peaks also occur which most likely represent Laue reflections. 


\subsection{Optical Properties}

Our studies of the electro-optical properties of the $\mathrm{Bi}_{3}$ crystals involve the optical absorption studies between 0.6 and $50 \mu \mathrm{m}$, from which the energy gap $E_{g}$ and the complex index of refraction could be evaluated.

Energy band gap measurements have been made at two temperatures on single Bi I3 crystals cleaved perpendicular to the crystallographic $C_{3}$ axis (hexagonal " $c$ " axis). The results are shown in Table 2 below and compared with values published by V.I. Vashchenko and V.B. Timofeev ${ }^{2}$ for the same crystallographic plane.

Table 2. Energy gap, $\mathrm{Eg}$, in $\mathrm{eV}$ as a function of the temperature $\mathrm{T}\left({ }^{\circ} \mathrm{K}\right)$ for $\mathrm{BiI}_{3}$ crystals

\begin{tabular}{|c|c|c|}
\hline$T\left({ }^{\circ} \mathrm{K}\right)$ & $\begin{array}{c}\mathrm{E}_{\mathrm{g}} \\
\text { Present Work }\end{array}$ & $\begin{array}{c}\mathrm{E}_{\mathrm{g}} \\
\text { Reference 2 }\end{array}$ \\
\hline 293 & 1.78 & 1.73 \\
85 & -- & 1.93 \\
78 & 2.04 & -- \\
\hline
\end{tabular}

We were unable to detect any absorption at $11.9 \mu \mathrm{m}$ as reported by the above authors. ${ }^{2}$ We did, however, observe absorption at $40 \mu \mathrm{m}$, as may be seen in the composite graph in Fig. 3, which shows the transmission perpendicular to the cleaved plane for two wavelength ranges: 0.6 to $1.5 \mu \mathrm{m}$ and 2.5 to $50 \mu \mathrm{m}$. The oscillations on the graph are caused by interfering multiple reflections from the two surfaces of the crystal which form a etalon.

M.P. Lisitsa ${ }^{8}$ has developed formulas for the calculation of the complex index of refraction which account for multiple internal reflections. We have used these formulae to calculate the complex index at 1 im associated with the wavelength of neodymium-doped YAG lasers.

We evaluate the complex index of refraction

$$
N=n-i k
$$


where $n$ and $k$ are the real and imaginary parts of the complex index with

$$
\begin{aligned}
& n=\frac{1+R+\sqrt{4 R-(1-R)^{2} k^{2}}}{1-R} \\
& k=\frac{\lambda}{8 \pi d} \ln \frac{R(R[n-2]+1)}{n-R} \\
& R=\frac{D^{2}-n^{2}+2 n+1-\sqrt{\left(D^{2}-n^{2}+2 n+1\right)^{2}-4 n(2-n)}}{2(2-n)^{2}} \text { (* see footnote) }
\end{aligned}
$$

where $R$ is the coefficient of surface reflection, $d$ is the crystal layer thickness, $D$ and $n$ are the measured transmission and reflection coefficients.

In our studies the relationships $D=0.56, n=0.41$, and $d=7.6 \times 10^{-3} \mathrm{~cm}$ give a complex index refraction of

$$
N=3.13-i\left(3.2 \times 10^{-5}\right)
$$

\subsection{Gamma-Ray Detection}

Aquadag contacts were placed on undamaged sections of a cleaved [0001] slice and of a non-purified $\mathrm{BiI}_{3}$ crystal, which allowed measurement of the current voltage characteristics in the dark. Currents on the order of microamps at voltages below $100 \mathrm{~V}$ were observed. When the crystal was exposed to light, it showed some increase in current due to photoconductivity, but not very much (factors of two with a $100-V$ bulb one foot away).

One cleaved [0001] slice of a purified ingot of $\mathrm{BiI}_{3}$ (four times resublimed) has been subsequently tested. Instead of Aquadag contacts, evaporated gold was used. Currents were considerably smaller, on the order of nanoamps with voltages up to several hundred volts. This value of current is what one would expect, roughly, from the band gap of the material in conduction. Photoconductivity was quite marked when the box was open to room lighting.

* We note in the English translation of Lisitsa's paper that his expression for $R$, the solution of a quadratic equation, should use the minus sign (rather than the plus sign) in front of the square root. If the plus sign is used the result is the physically impossible situation where $R$ is greater than $n$ and the total reflected and transmitted radiation will exceed 100 percent. 


\section{ACKNOWLEDGMENTS}

We would like to express our thanks to Dr. T. Davis for helpful discussion of the manuscript, to Dr. R. Millikan of UCSB, Chemistry Dept., for use of his Perkin Elmer Spectrometer, and to Dr. J. Llacer of UCLA for the photoconductivity mea surements. 


\section{LIST OF REFERENCES}

1. R.I. Shekhmamet'ev, Sov. Physics Solid-State (English) 3, 426, 1961.

2. V.I. Veshchenko and V.B. Timofeev, Sov. Physics Solid-State, 9, 1242, 1967.

3. E. Mooser and W.B. Pearson, Acts Cryst., 12, 1015, 1959.

4. L. Bergmann and J. Hansler, Z. Phys., 100, 50, 1936.

5. S.J. Yosim, L.D. Ransom, R.A. Sallach, L.E. Topol, J. Phys. Chem., 63, 245, 1959.

6. D. Cubiciotti and F.J. Keneshea, J. Phys. Chem., 63, 295, 1959.

7. GmeZin's Handbuch der Anorg., Chemie 8th Edition, Bismuth Supplement Volume, System 19, 1964.

8. M.P. Lisitsa, Sov. Phys., Dokladyakad. Nauki, (English) 1, 716, 1956. 


\section{LIST OF FIGURE CAPTIONS}

Figure 1: Temperature profile of furnace

Figure 2: Boule of $\mathrm{BiI}_{3}$

Figure 3: Optical transmission of $\mathrm{BiI}_{3}$ between 0.6 and $1.5 \mu \mathrm{m}$ and 2.5 to $50 \mu \mathrm{m}$ 


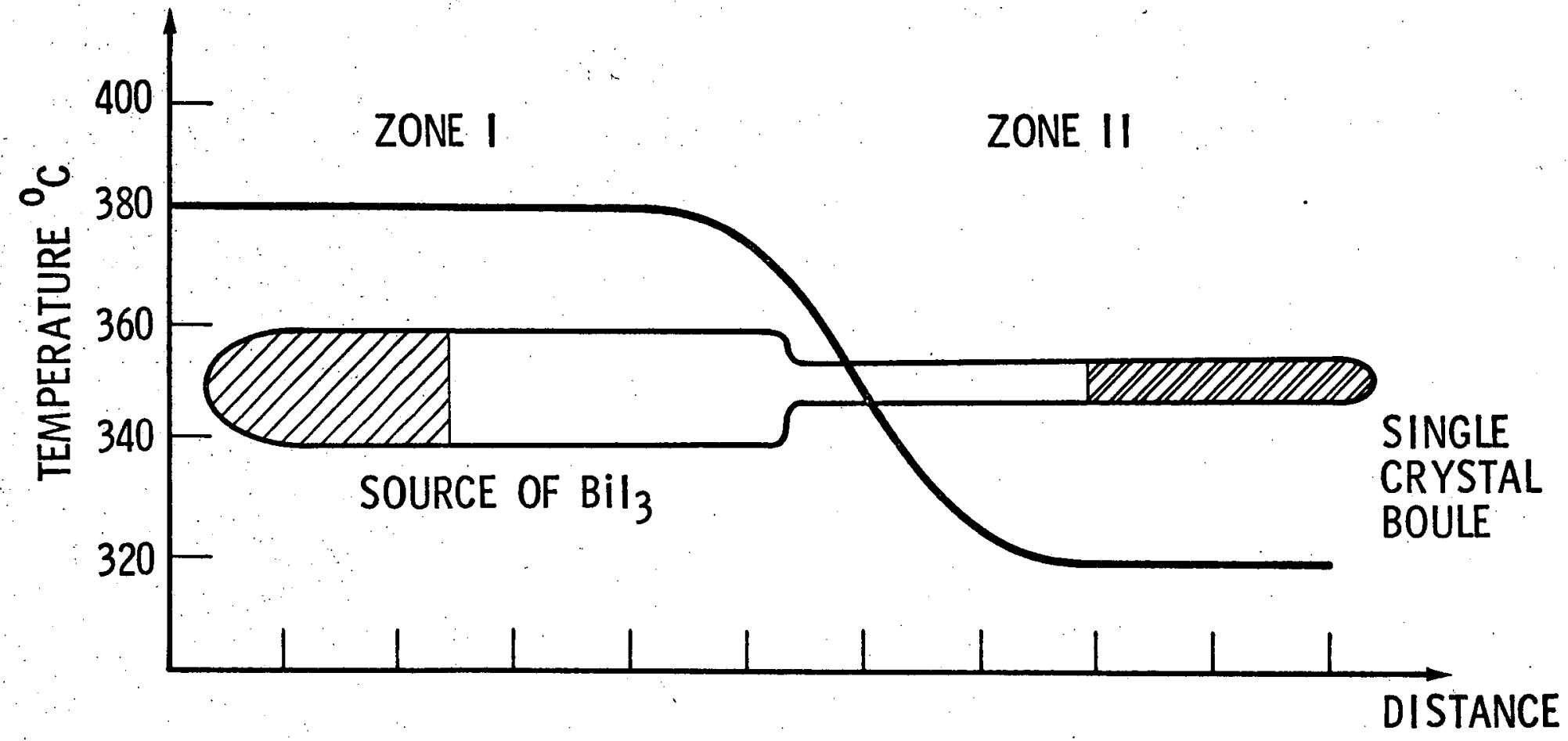




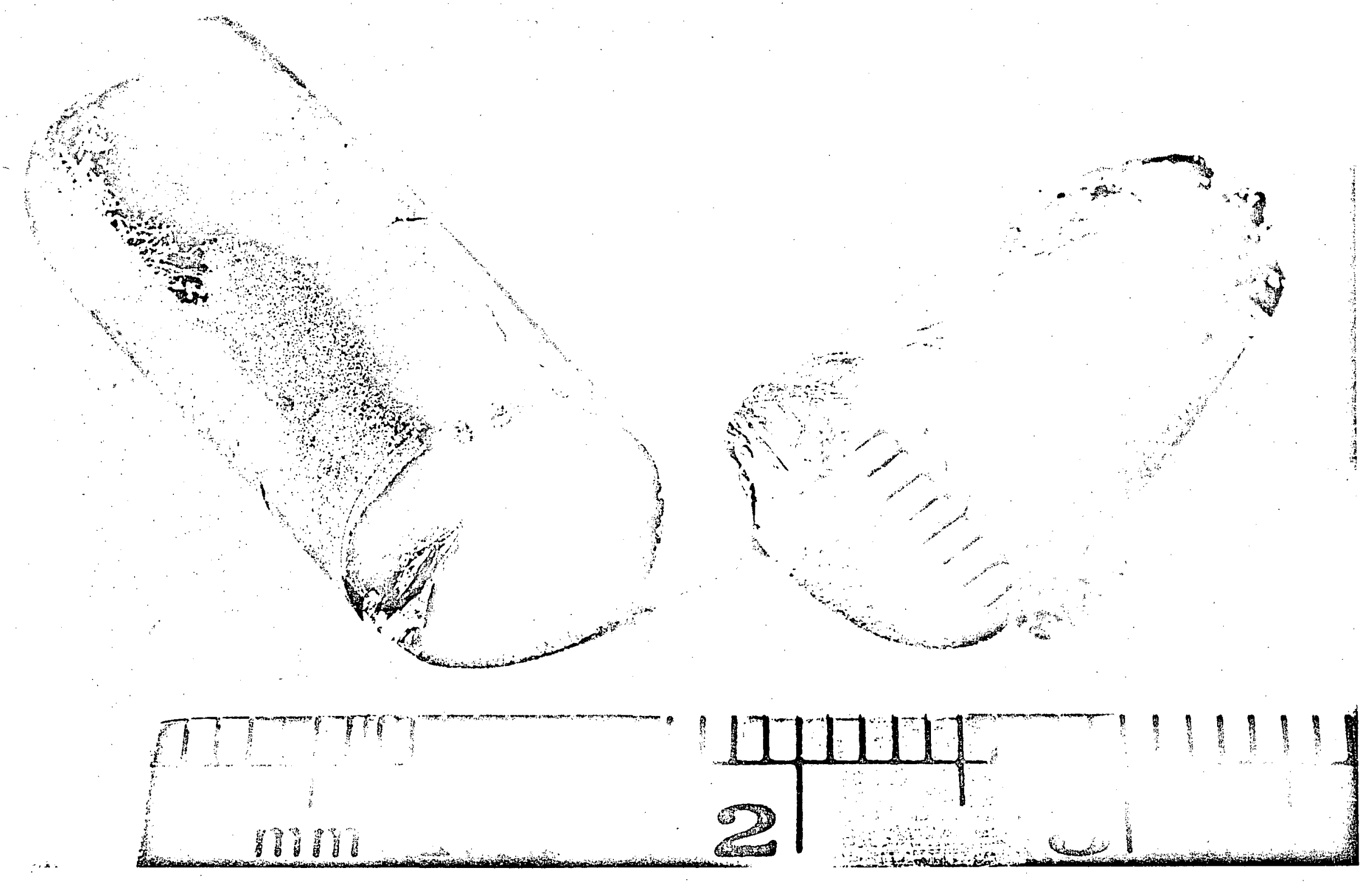



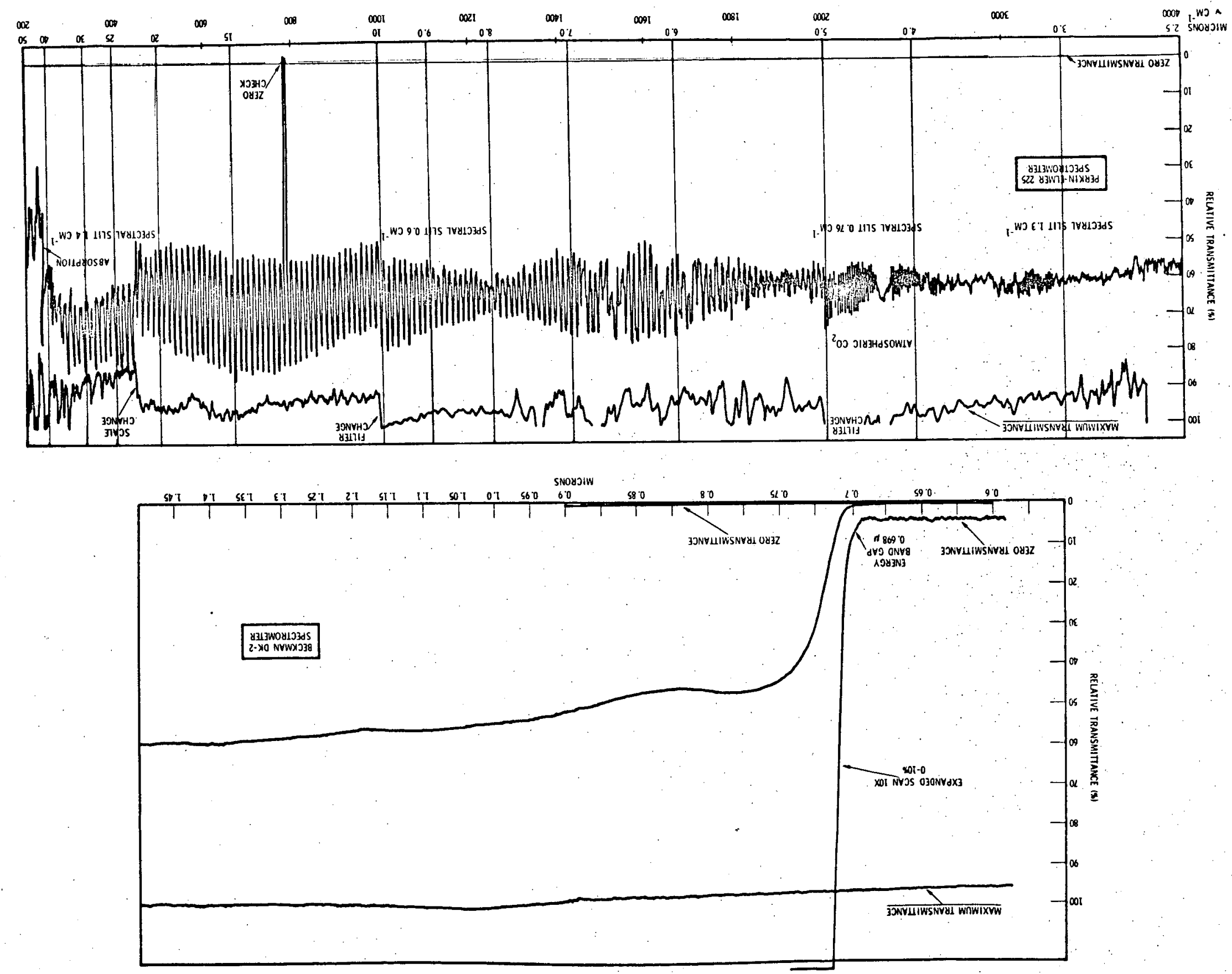


\section{DISTRIBUTION}

AEC, NVO

J. Koch

L. Loux

R. Purcell

AEC, TIC, Oak Ridge

T. Abernathy (2)

\section{EG\&G Bedford}

R. Cadwallader

EG\&G Santa Barbara Division

M.M. Schieber

T.J. Davies

H.A. Lamonds

W.F. Schnepple

R.C. Carlston

Contracts

Publications (3) 